\title{
Overview of the Main Propulsion System for the NASA Ares I Upper Stage
}

\author{
Jason E. Quinn ${ }^{1}$ \\ NASA MSFC, AL, 35812 \\ and \\ Luke A. Swanson ${ }^{2}$ \\ ERC Inc., NASA MSFC, AL 35812
}

\begin{abstract}
A functional overview of the Main Propulsion System (MPS) of the NASA Ares I Upper Stage is provided. In addition to a simple overview of the key MPS functions and design philosophies, major lessons learned are discussed. The intent is to provide a technical overview with enough detail to allow engineers outside of the MPS Integrated Product Team (IPT) to develop a rough understanding of MPS operations, components, design philosophy, and lessons learned.
\end{abstract}

\section{Introduction}

NASA plans to utilize the Ares I vehicle to transport astronauts to low earth orbit after the space shuttle's scheduled retirement in 2010. An expanded view of the entire Ares I vehicle is shown in Figure 1. The Ares I vehicle is composed of three main sections: First stage, Upper stage, and Orion. Shown to the right of the expanded view of the Ares I is an enlarged cross-section of the Upper Stage (US) showing the major components of the US: Instrumentation Unit, Liquid Hydrogen (LH2) Tank, Liquid Oxygen (LO2) Tank, and Upper Stage Engine (USE or $\mathrm{J}-2 \mathrm{X})$.

\footnotetext{
${ }^{1}$ Integrated Product Team Lead, ARES 1 Upper Stage Main Propulsion System, ER22.

${ }^{2}$ Propulsion Systems Engineer, ARES 1 Upper Stage Main Propulsion System, ER22.
} 


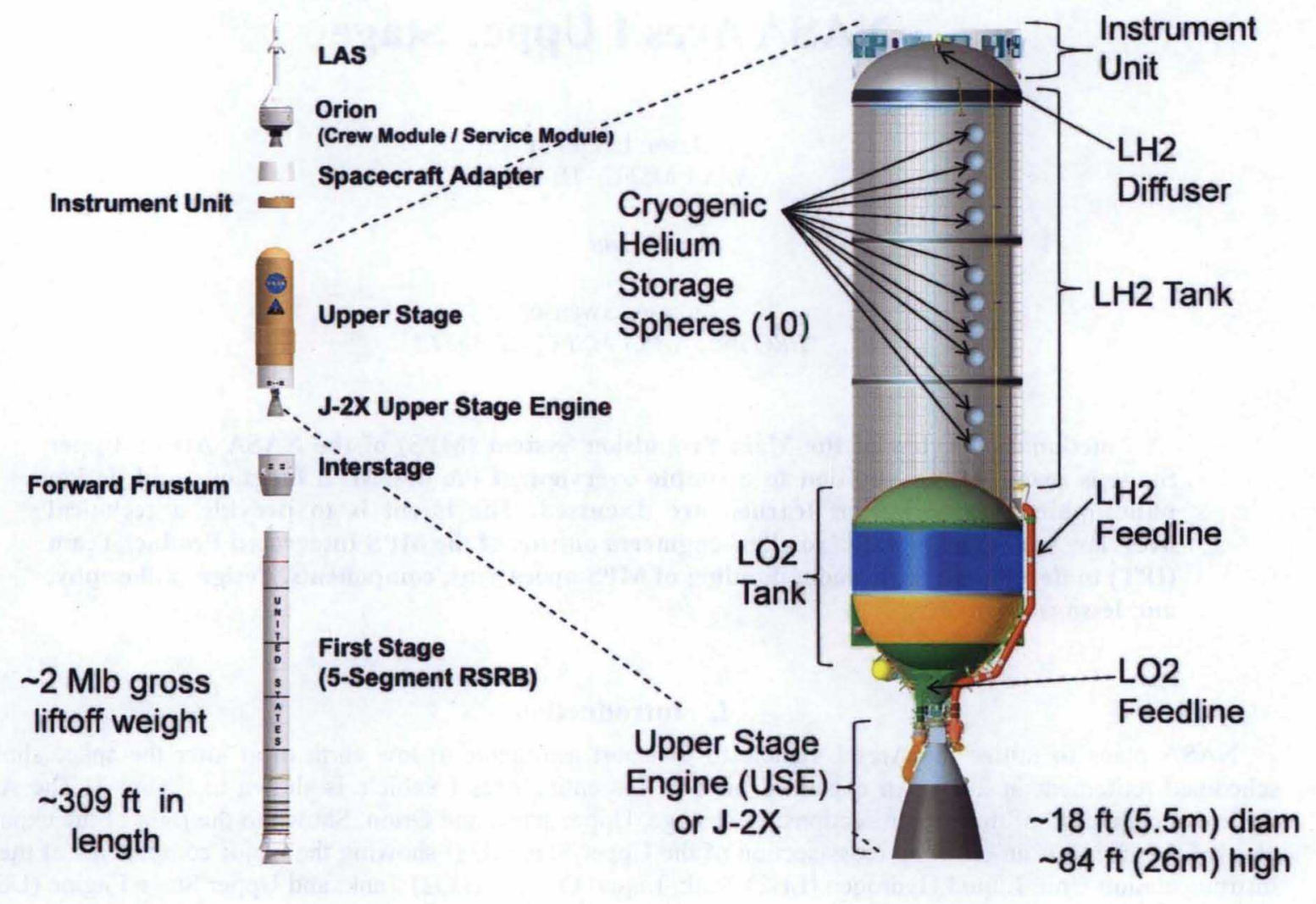

Figure 1: Expanded view of Ares I launch vehicle and enlarged cross-section of the Upper Stage

The MPS includes everything needed to provide the USE with the required LO2, LH2 and pressurant gases to support Upper Stage flight. MPS includes the LH2 feedline (Figure 1), ten cryogenic helium storage spheres inside of the LH2 tank, ullage gas inside of the LH2 tank above the LH2, and even the LH2 itself but does NOT include the LH2 tank as this is considered a structure (and designed by the Structures and Thermal design team). Excluding the LH2 and LO2 tanks and the umbilical plates, MPS includes any component that contains/controls fluid that goes to the USE. The instrumentation requirements, fluid control algorithms, control electronics, and a portion of the mounting design are included in the MPS design responsibility, although instrumentation and avionics (Flight Computer) used for control are not.

Figure 2 shows the standard orthographic projections of the US as it would look immediately after USE shutdown and Orion separation - with all of the fairings and thrust cone thermal blanket removed. The fairings are the covers over the various pipes and projections that "stick out" of the stage and provide aerodynamic/acoustic protection. The primary "front" view, in Figure 2, is the side of the stage that would be facing the Mobile Launch Platform (MLP) - this is the easiest view to identify as the LH2 feedline and umbilical plates are on this side of the stage. Immediately above this view is the "top" view where the LH2 vent line can be seen routing gaseous hydrogen from the top of the LH2 tank to the umbilical plate. Below the "front" view is the "bottom" view which is looking up the nozzle of the USE. Although MPS components are located throughout the stage the majority are located on the thrust cone. 


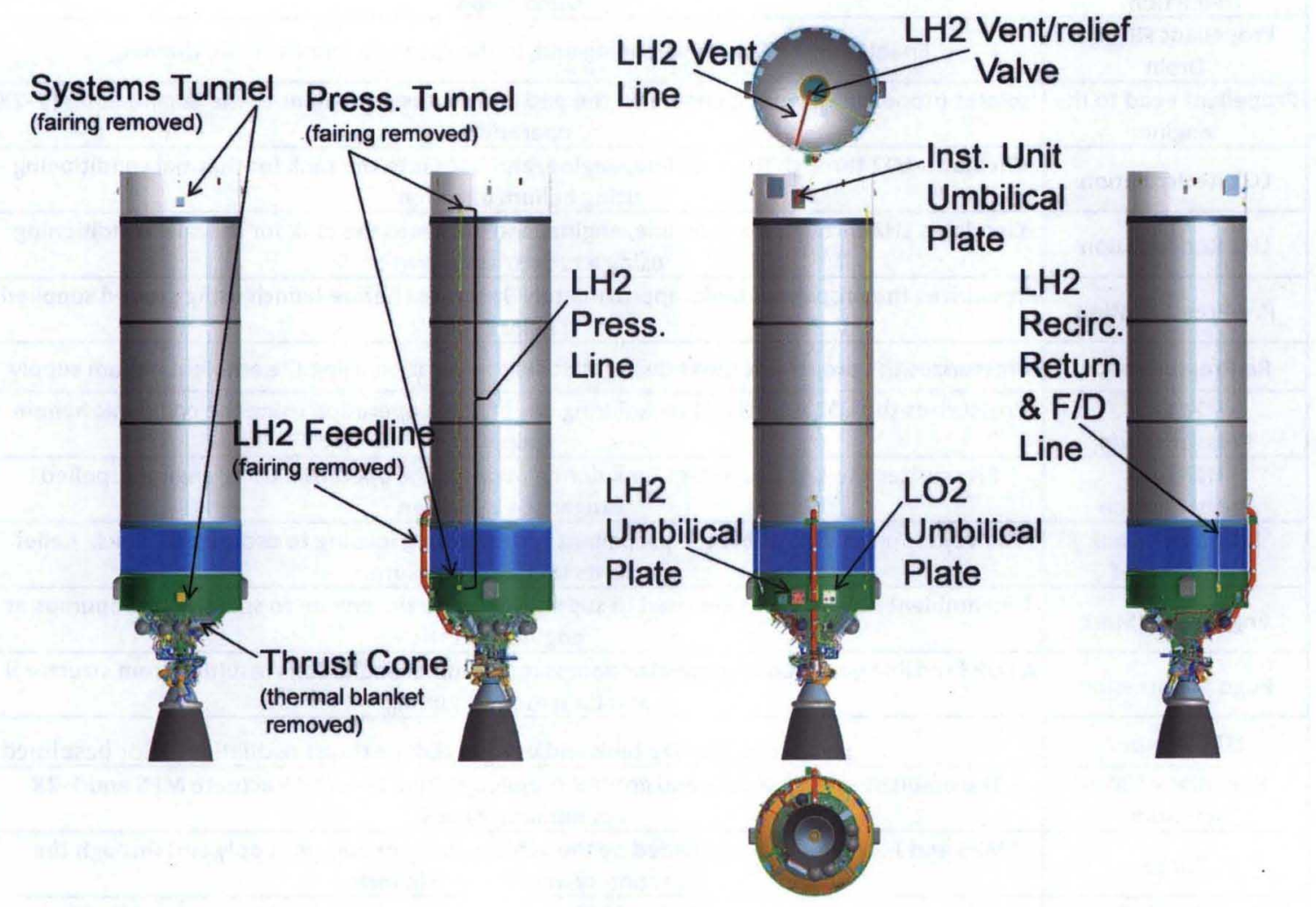

Figure 2: Ares I Upper Stage exterior views

The MPS is required to provide the USE with LO2, LH2 and pneumatic/purge gases to support Upper Stage flight. Generally these propellants are provided within specified pressure and temperature ranges with the USE components setting the flow rate. A more detailed list of the general functions that MPS has been designed to perform are listed in Table 1. The primary MPS schematic showing all of our system level components and their fluid connections is shown in Figure 3. This schematic is intended to show interconnectivity and does not show positional relationships. Somewhat ironically, the longest MPS line on the stage (the LH2 pressurization line - see Figure 2) is shown as the shortest line on this schematic. 
Table 1: Summary list of primary Main Propulsion System functions

\begin{tabular}{|c|c|}
\hline Function & Description \\
\hline $\begin{array}{l}\text { Propellant Fill and } \\
\text { Drain }\end{array}$ & Enables propellant tank loading and, in the case of a launch scrub, draining \\
\hline $\begin{array}{l}\text { Propellant Feed to the } \\
\text { engine }\end{array}$ & $\begin{array}{c}\text { Isolates propellant from the engine on the pad and routes propellant to the engine during } \mathrm{J}-2 \mathrm{X} \\
\text { operation }\end{array}$ \\
\hline LO2 Recirculation & $\begin{array}{l}\text { Circulates LO2 through the feed line, engine, and back into the tank for thermal conditioning } \\
\text { using helium injection }\end{array}$ \\
\hline LH2 Recirculation & $\begin{array}{l}\text { Circulates LH2 through the feed line, engine, and back into the tank for thermal conditioning } \\
\text { using a recirculation pump }\end{array}$ \\
\hline Pre-Pressurization & $\begin{array}{l}\text { Pressurizes the propellant tanks approximately } 3 \text { minutes before launch using ground supplied } \\
\text { helium }\end{array}$ \\
\hline Re-Pressurization & Pressurizes the propellant tanks during first stage operation using the ambient helium supply \\
\hline $\begin{array}{l}\text { LO2 Tank } \\
\text { Pressurization }\end{array}$ & $\begin{array}{l}\text { Pressurizes the LO2 propellant tank during upper stage operation using the cryogenic helium } \\
\text { supply }\end{array}$ \\
\hline $\begin{array}{c}\text { LH2 Tank } \\
\text { Pressurization }\end{array}$ & $\begin{array}{l}\text { Pressurizes the LH2 propellant tank during upper stage operation using engine supplied } \\
\text { autogenous hydrogen }\end{array}$ \\
\hline $\begin{array}{l}\text { Propellant Tank } \\
\text { Vent/Relief }\end{array}$ & $\begin{array}{c}\text { The vent is opened to allow the propellant boiloff during loading to escape the tanks. Relief } \\
\text { prevents tank overpressure. }\end{array}$ \\
\hline Engine Spin Start & $\begin{array}{c}\text { Two ambient helium tanks are used to supply helium to the engine to spin the turbopumps at } \\
\text { engine start }\end{array}$ \\
\hline Pogo Suppression & $\begin{array}{l}\text { A LO2 feed line gas filled accumulator damps longitudinal oscillations resulting from structural } \\
\text { and fluid mode coupling }\end{array}$ \\
\hline LO2 Damper & Located in the LO2 tank and used to reduce thrust oscillation *Not baselined \\
\hline $\begin{array}{l}\text { Pneumatic Valve } \\
\text { Actuation }\end{array}$ & $\begin{array}{l}\text { The ambient helium supply and ground supplied helium is used to actuate MPS and J }-2 \mathrm{X} \\
\text { pneumatic valves }\end{array}$ \\
\hline Purge & $\begin{array}{l}\text { MPS and J-2X purges are provided by the vehicle ambient helium supply and through the } \\
\text { ground systems before launch }\end{array}$ \\
\hline $\begin{array}{l}\text { TVC Hydraulic Power } \\
\text { Supply }\end{array}$ & $\begin{array}{l}\text { TVC is supplied gas from both the MPS ambient helium supply and from a tap off of the } \\
\text { autogenous LH2 pressurization line }\end{array}$ \\
\hline $\mathrm{J}-2 \mathrm{X}$ engine Drains & Oxygen and helium is routed away from the engine and drained overboard \\
\hline
\end{tabular}




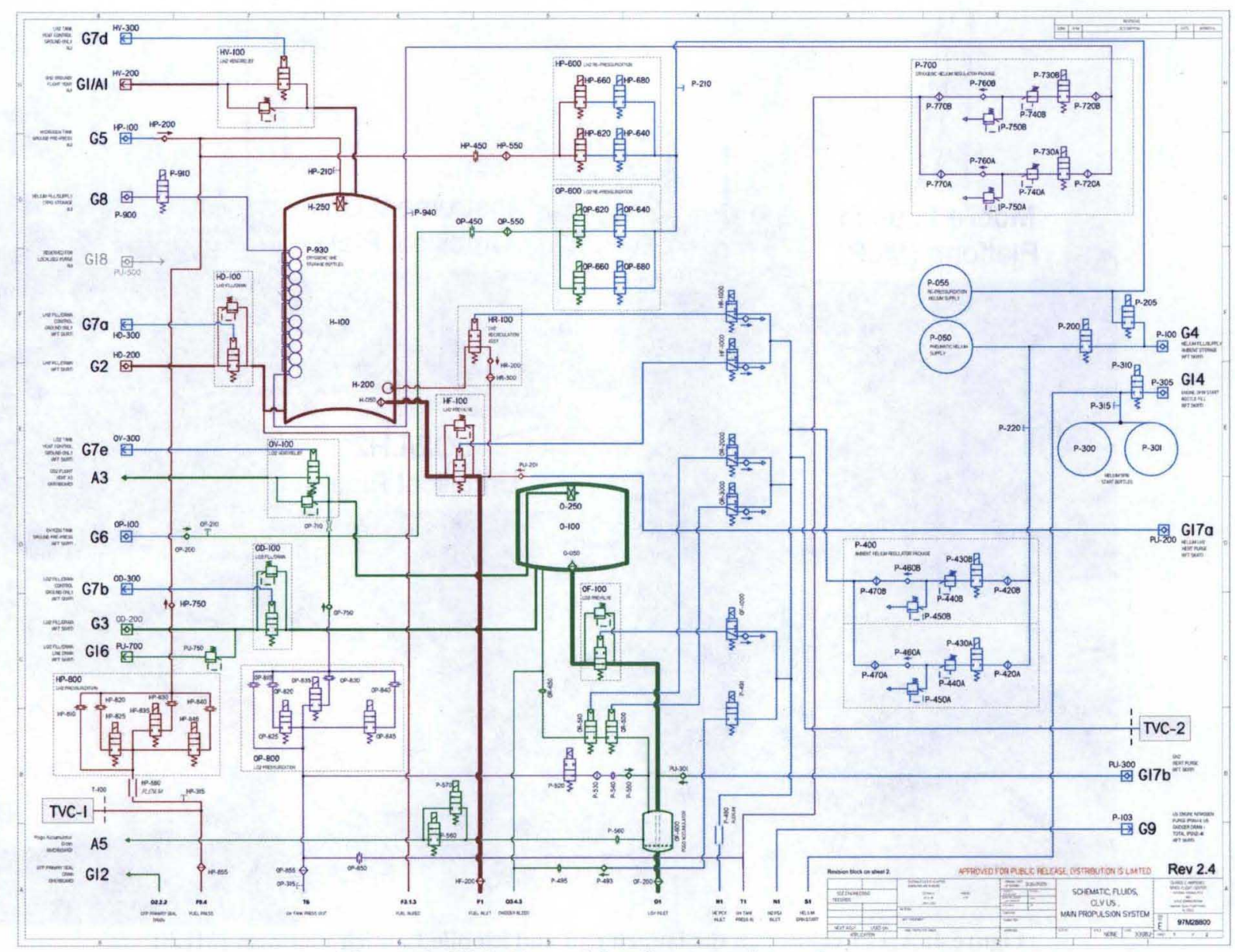

Figure 3: Main Propulsion System schematic

The core of this paper steps through the operations of the Upper Stage from call-to-stations, where cryogenic propellant loading is started, through flight operations and finally stage disposal into the ocean. After the system operations are explained, the design process and team structure is very briefly reviewed along with several of the more important lessons learned by the design team.

\section{MPS Operational Walk Through}

MPS begins as a "big bag-of-parts" at Michoud Assembly Facility (MAF) in New Orleans. This is where the various MPS vendors ship their components for assembly onto the US as it is being manufactured. As MPS is completely integral to the US it does not exist as a "system" until it is built up along with the rest of the US. Once build up of the US is complete, the US is placed on a barge and sent to Stennis Space Center for a test firing (note only the first few stages built will be test fired). After the test firing the stage is shipped back to MAF for checkout and then barged to Kennedy Space Center (KSC). At KSC, the Upper Stage is stacked, along with the first stage and Orion, into a complete ARES 1 vehicle on the Mobile Launch Platform (MLP). Several days prior to launch, the MLP and ARES I stack is rolled out to the launch pad and ground system fluid connections are made, which include the propellant fill and drain interfaces. Figure 4 shows the ARES I vehicle on the MLP at the launch pad with the umbilical arms connecting the vehicle to the MLP through the umbilical plates. 


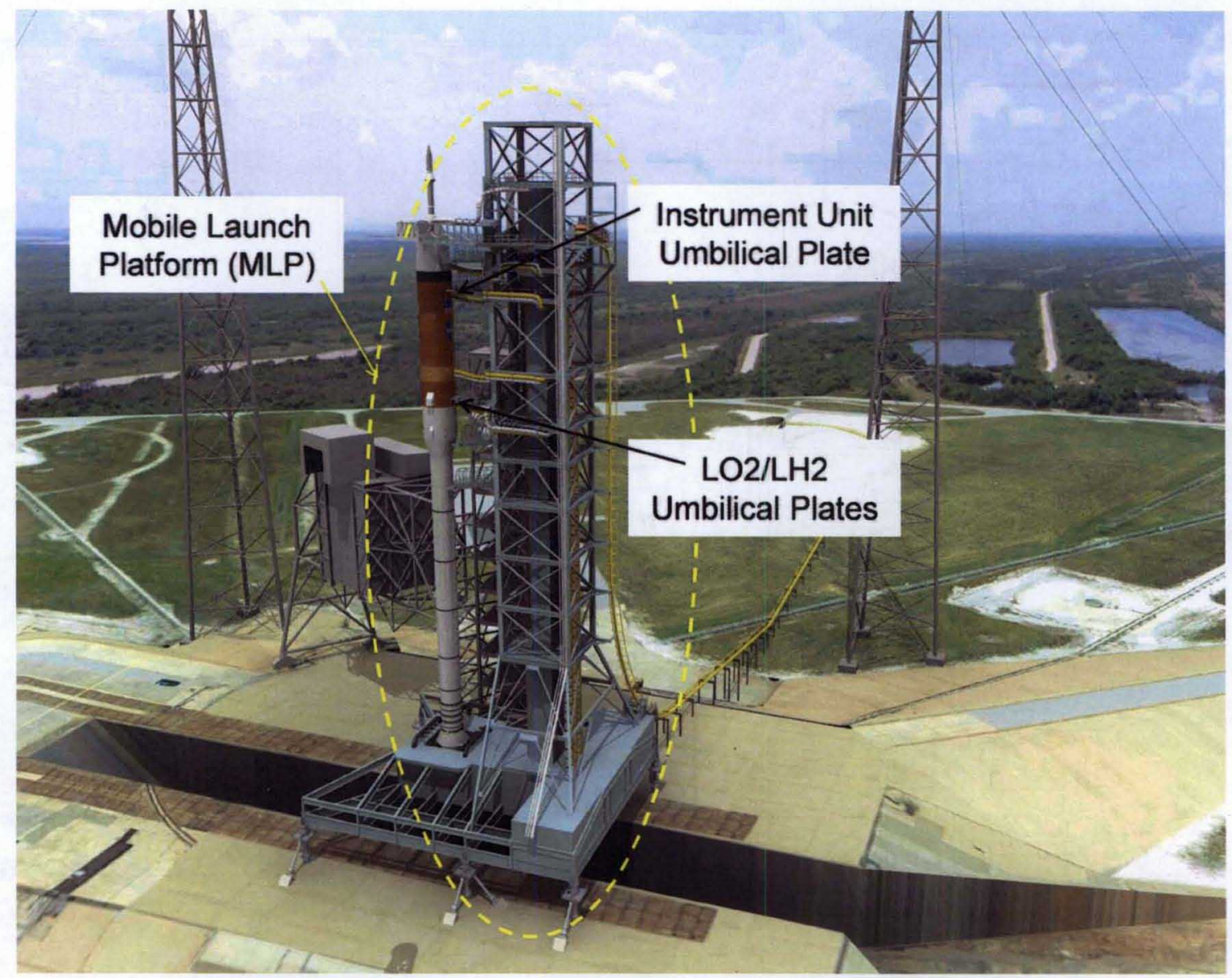

Figure 4: Ares I vehicle on the launch pad and Mobile Launch Platform (MLP)

Once the ARES I vehicle is on the launch pad, the stage is ready for checkout, final servicing, and propellant loading. Figure 5 shows the top level MPS functions in a simplified timeline format. This Gantt chart assumes minimum times for each function prior to launch. Note that the time scale, across the top of the chart, changes in order to show the functions durations - days, hours then minutes and seconds for the flight operations. The intent is to show the propellant loading, primary MPS functions as the vehicle is prepared to launch, and flight functions through USE shutdown. By stepping through this simplified MPS operations timeline the reader can gain an overview of what MPS does for the stage. 


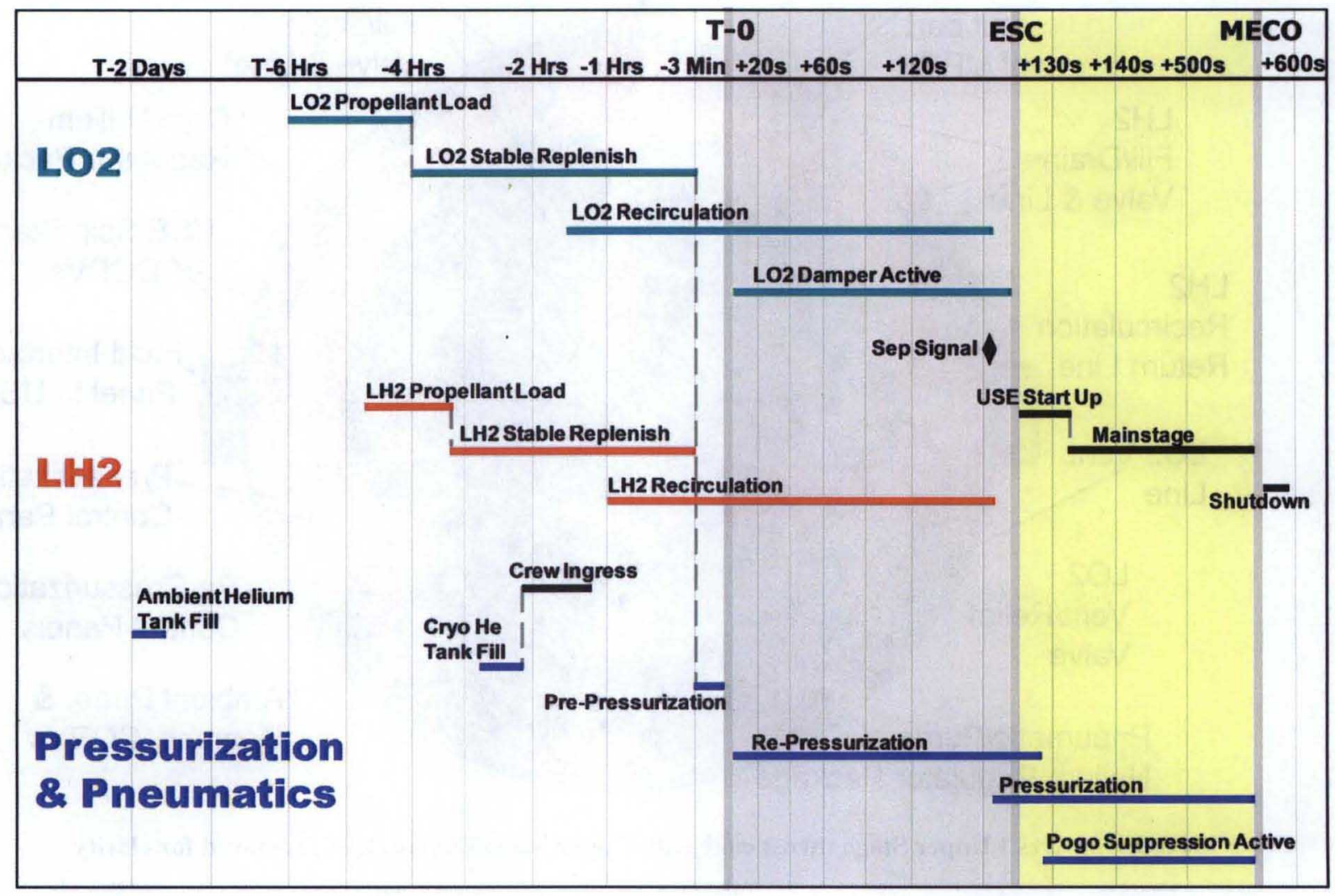

Figure 5: Main Propulsion System simplified operations timeline

\section{A. Ambient Helium Loading}

The ARES I US MPS Simplified Timeline begins two days prior to launch (labeled T-2 days on the top of the chart) when the four ambient helium Composite Overwrapped Pressure Vessel (COPV) spheres on the thrust cone (see Figure 6) are filled with helium. This filling process takes several hours as the filling process is required to be slow to prevent exceeding the composite overwrap temperature limit. Since the COPV filling process is considered hazardous and requires the launch pad to be cleared, it is performed two days prior to launch at the same time as the hazardous loading of the Reaction Control System (RCS) storable propellants. (RCS is not considered part of MPS). 


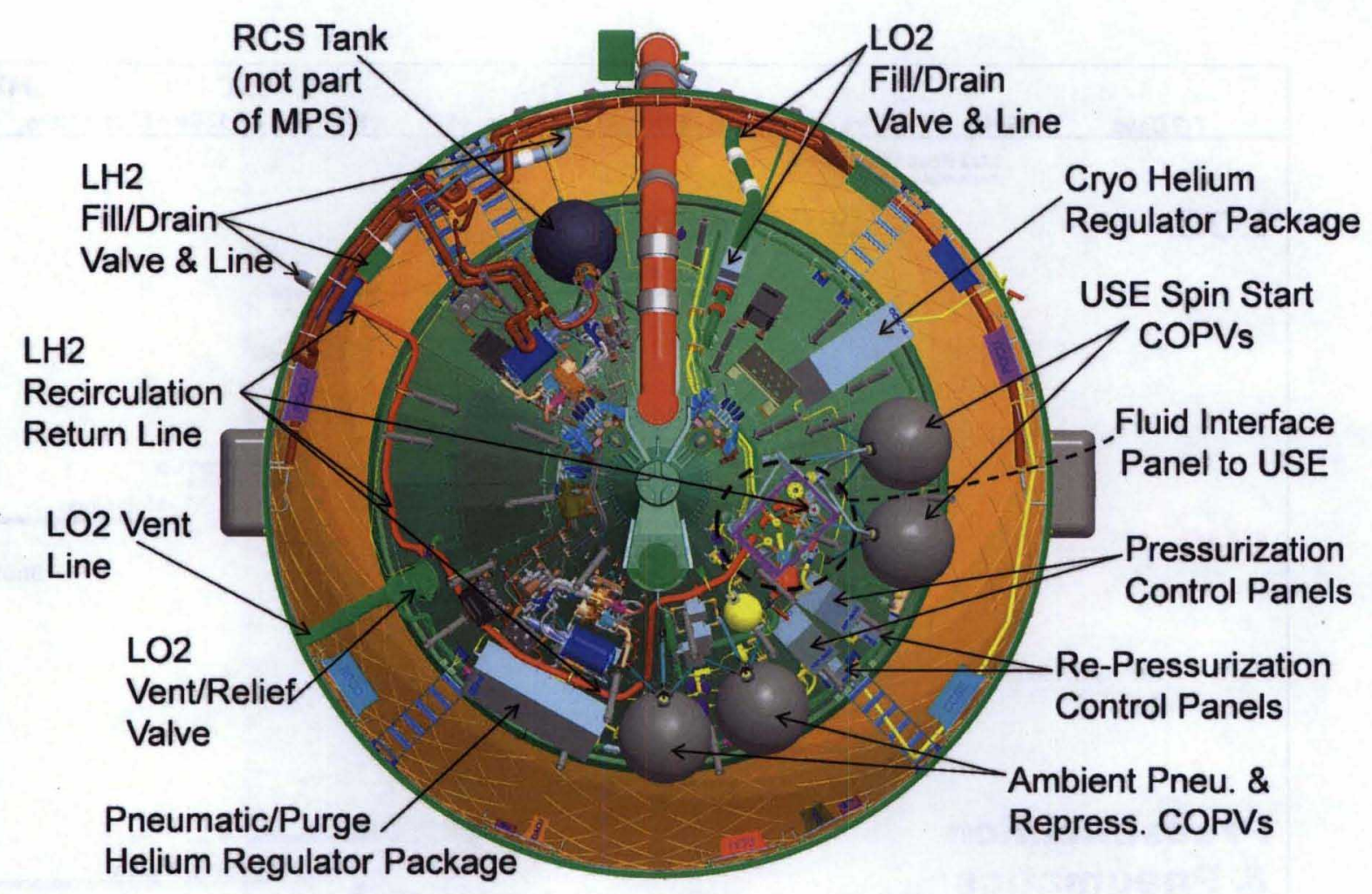

Figure 6: Ares I Upper Stage thrust cone with Upper Stage Engine (USE) removed for clarity

The thrust cone, shown in Figure 6, has the USE and the thrust cone thermal blanket removed so that the MPS components on the thrust cone can be seen. The four ambient COPVs located on the thrust cone are used for different functions. One COPV is used for pneumatics and purges - primarily for USE functions - and a second $\mathrm{COPV}$ is used for repressurization. These two spheres are loaded to 4500 psia but are used as separate volumes in order to allow more of the helium in the repressurization sphere to be used while not going below the low temperature limit for helium supplied to the USE. The remaining two USE Spin Start COPVs are loaded to a lower pressure ( $3100 \mathrm{psia})$ than the pneumatic and repressurization spheres and are interconnected to form a single volume. In order to save cost, the four COPVs are intended to have an identical metallic liner with more composite overwrap on the pneumatic and repressurization spheres to handle the higher pressure.

Unlike the J-2 engine used on the Saturn V launch vehicle, the USE (or J-2X) uses a MPS supply of ambient helium (rather than an engine supplied source) to spin up the engine turbopumps for a rapid start. The spin start ambient helium has no valves between the engine interface and the COPVs (simply a tank and some piping). Only a single start of the USE is possible with this spin start helium supply configuration.

Pneumatic and purge helium is regulated from the high pressure COPV to a nominal $750 \mathrm{psig}$ and supplied to the MPS and USE systems. This helium is used on the Upper Stage for LO2 recirculation (discussed below) and to actuate large pneumatic valves in the MPS: Prevalves, Fill \& Drain valves, Recirculation Isolation valve and POGO bleed valves. Regulated helium is also supplied to the USE for pneumatic valve actuation and for purges. This regulated helium is available once the ambient helium sphere is filled above 1200 psig and the flight computer is powered and able to actuate the isolation solenoids open (although not further discussed, these solenoids can be seen in Figure 3). Regulated helium is supplied the majority of the time the stage is on the pad and is required to be available throughout flight.

Once regulated helium pressure is supplied to the USE, the USE drains become active. For example, the InterPropellant Seal (IPS) purge is always active as there are no control valves (only check valves for contamination control) on the USE between the stage supplied helium and the drain to the outside environment. Potentially hazardous oxygen and hydrogen drains are required to route the contents back to the MPS through the Fluid Interface Panel to USE (See Figure 6) and then overboard. Exterior drain plugs are removed at the launch pad and 
the ambient helium supply from MPS to the USE must be started within eight hours of drain plug removal for contamination control. USE drains that are permitted to flow into the interior of the interstage are not considered part of MPS as they simply terminate where appropriate for the USE. Interior drain plugs are removed at the Vehicle Assembly Building (VAB) during stage assembly as the interior of the Upper Stage is considered a controlled environment (it is purged with GN2 while at the VAB \& launch pad). The largest drain in terms of flow rate and size is the USE nozzle itself, which has a nitrogen purge prior to loading cryogens and then transitions to a helium purge $(\sim 1200 \mathrm{scfm})$. The environmental GN2 purges for the inside of the Upper Stage compartments are not considered part of MPS and are designed by the Hazardous Gases design team.

\section{B. Propellant Loading}

Once the launch director is satisfied that the ARES I vehicle and crew are ready for the mission, NASA schedules the call-to-stations and begins the countdown to launch. LO2 tank loading is the first MPS process, after call-to-stations. This is performed by using ground facility pumps to pull the LO2 from the ground storage tanks and push the LO2 to the MLP and up to the Upper Stage umbilical plate connections (see Figure 4). The LO2 sealing quick disconnect (QD) connects the flight vehicle to the ground at the umbilical plates. The LO2 passes through the LO2 sealing QD, through the LO2 fill and drain (F/D) valve and into the LO2 tank (see Figure 6). A portion of the LO2 boils-off and enters the LO2 diffuser travelling down the snorkel (Figure 7) and through the vent/relief valve and duct directly to the atmosphere (Figure 6). The sealing QD and F/D valve provide two barriers to overboard leakage while the vent/relief valve is only a single barrier. LO2 loading goes through a slow, fast and then topping fill process and is considered complete when the tank level is at the intended flight level. The stable replenish ground supplied flow rate is then set to maintain this desired level by balancing the steady state boil-off due to heat transfer into the LO2.

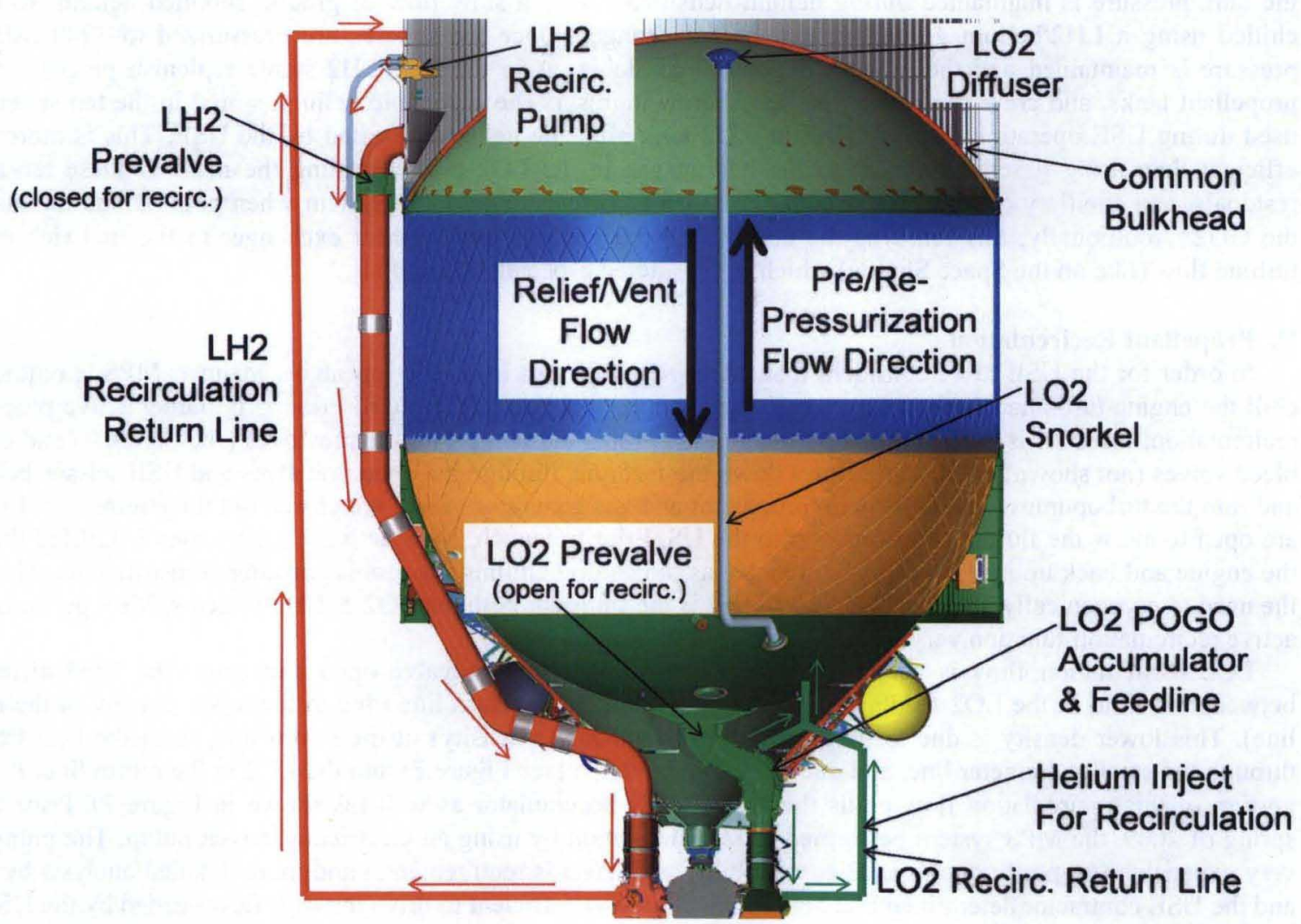

Figure 7: Section of the Ares I Upper Stage showing the LO2 tank and snorkel 
The LH2 loading process is started by pressurizing the ground facility storage tank and pushing the LH2 to the MLP and up to the US umbilical connection. The LH2 passes through the LH2 sealing QD, through the LH2 F/D valve and up the side of the stage to the LH2 tank (Figures $2 \& 6$ ). The boil-off of hydrogen gas is vented out of the $\mathrm{LH} 2 \mathrm{vent} / \mathrm{relief}$ valve, through the vent/relief duct, the Instrumentation Unit (IU) and umbilical plate, and to the ground system and flare stack (see Figure 2). Similar to the LO2 system the sealing QD and F/D valve provide two barriers to overboard leakage and the vent/relief valve is only a single barrier. LH2 loading goes through a slow, fast and then topping fill process and is considered complete when the tank level is at the intended flight level and the flow rate is set to maintain stable replenish.

Stable replenish is maintained for both of the propellant tanks for over one hour in order to allow the bulk propellant temperature to reach the boiling point corresponding to the pressure in the propellant tank ullage (which is close to the normal boiling point). The tanks venting systems are designed to have a pressure drop of less than 0.5 psi from the ullage to the atmosphere so that the propellant density (set by this ullage pressure and the resulting boiling temperature) reaches the design range. If the pressure in the ullage were to exceed the design value for a significant period of time, the boiling temperature will increase. This temperature increase results in a decrease in propellant density after the tanks are prepressurized to the specified level, resulting in a propellant quantity that is insufficient to perform the Ares I mission. The vent system also provides propellant tank relief in the event of tank over pressurization due to a failure. The vent/relief valves for both tanks, when closed (i.e. not venting), include a mechanical relief function which cannot be disabled and is always available to prevent pressure levels from exceeding the tank maximum design pressure.

\section{Cryogenic Helium Loading}

Once the LH2 propellant tank is full, the cryogenic helium tanks are filled with helium. The ten titanium spheres inside of the LH2 tank (See Figure 1) are slowly pressurized to 3200 psia with partially ground chilled helium, which slowly drops to near LH2 temperatures. This densification process occurs fairly quickly ( one hour), since the tank pressure is maintained during helium densification by a slow flow of ground supplied helium, which is chilled using a LH2/helium ground system heat exchanger. Once the spheres are pressurized to 3200 psia, the pressure is maintained and the process is considered stable, as in the LO2/LH2 stable replenish process for the propellant tanks, and crew can access the stage (crew ingress). The cryogenic helium, stored in the ten spheres, is used during USE operation to pressurize the LO2 tank after the helium is heated by the USE. This is more mass efficient than using gaseous oxygen, as the helium gas in the LO2 tank including the mass of these ten tanks, residuals, and ancillary components, weighs less than a corresponding GO2 system when you include the mass of the GO2. Additionally, this removes the need to have a gaseous oxygen heat exchanger in the fuel rich engine turbine flow (like on the Space Shuttle) which is considered especially hazardous.

\section{Propellant Recirculation}

In order for the USE to be confident that the engine will start in a very repeatable manner, MPS is required to chill the engine turbomachinery to cryogenic temperatures prior to engine start. Prior to initiating active propellant recirculation, the USE is partly chilled by loading the propellant tanks with the prevalves (see Figure 7) and engine bleed valves (not shown) open. Fluid flows down the feedline, through the open prevalves and USE scissor bellows, and into the turbopumps. The USE main propellant and gas generator valves are closed but the engine bleed valves are open to allow the fluid to flow back up to the US. Prior to launch, MPS actively recirculates LO2/LH2 through the engine and back up into the propellant tanks, as the natural chilling process is considered insufficient. Although the need to cryogenically chill the turbomachinery is the same for both the LO2 \& LH2 systems, MPS performs this active recirculation function very differently in each of those systems.

LO2 recirculation flow is accomplished by leaving the LO2 prevalve open and using the head difference between the fluid in the $\mathrm{LO} 2$ feedline and the $\mathrm{LO} 2$ recirculation return line (due to the lower density in the return line). This lower density is due to the warmer LO2 (and lower density) in the return line, from the heat transfer through the smaller diameter line, and due to helium injection (see Figure 7) into the LO2 in the return line. A small portion of this recirculation flow chills the LO2 POGO accumulator as well (as shown in Figure 7). Prior to the spring of 2009, the MPS system performed LO2 recirculation by using an electrically driven pump. The pump was very expensive (primarily due to LO2 compatibility and hazards requirements) and more detailed analysis by MPS and the USE contractor determined that helium injection was sufficient to drive the chill flow needed by the USE.

LH2 recirculation flow is accomplished with an electrically driven LH2 recirculation pump that bypasses the closed prevalve and pushes the LH2 down the feedline and into the engine (See Figure 7). The LH2 then flows through the USE scissors ducts, through the LH2 turbopump, out the USE bleed valve, and back up to the MPS LH2 
recirculation return line. The LH2 recirculation return line snakes around the thrust cone (see Figure 6) before returning up the outside of the stage and into the bottom of the LH2 tank (Figure $1 \& 7$ ).

\section{E. LO2 Damper}

The LO2 damper is a new system (not yet part of the baseline design) within the MPS as of the summer of 2009. A notional concept of the LO2 damper is located in the bottom of the LO2 tank as shown in Figure 8. The LO2 damper is a passive device which causes the fluid in the LO2 tank to slosh vertically out of phase with the vehicle thrust oscillation loads that are potentially induced by the first stage five segment solid rocket motor. This out of phase sloshing reduces the vehicle response to the thrust oscillation loads, ultimately reducing the acceleration loads imposed on the crew. The LO2 damper is charged with helium prior to prepressurization and functions throughout first stage boost. It is omitted from the majority of the figures in this paper as it is still in the conceptual design phase (pre Systems Requirements Review). MPS has been tasked with "catching up" the design of the LO2 damper to the same level as the rest of the MPS system by our Critical Design Review at the end of 2010.

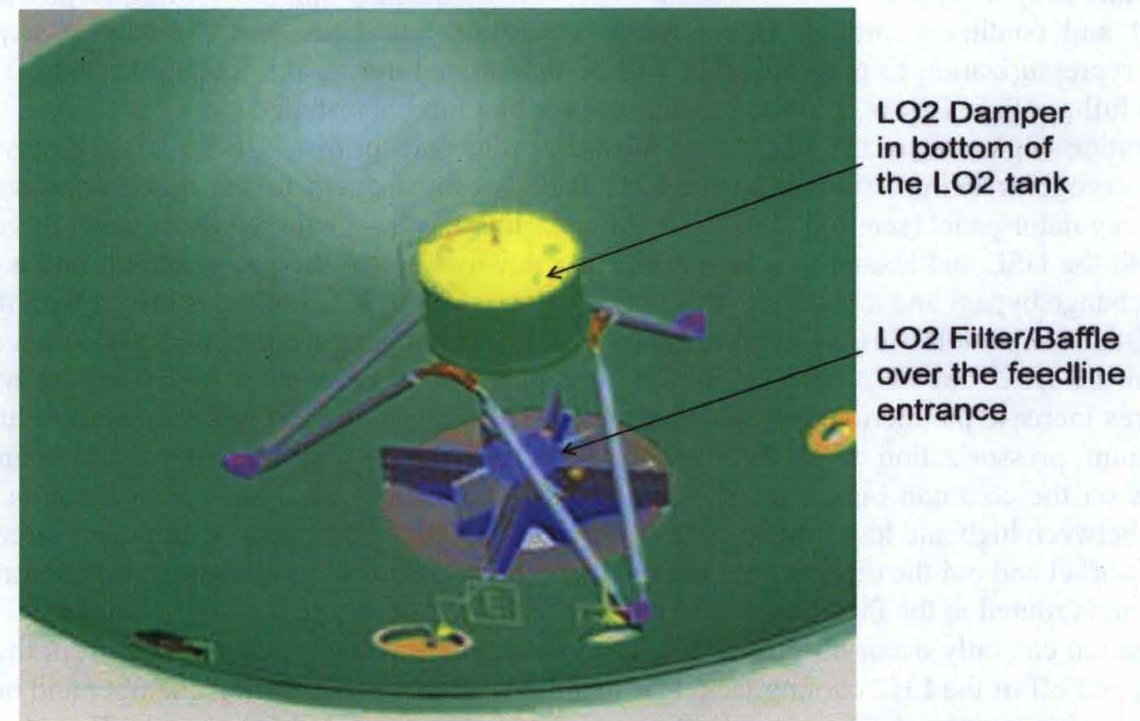

Figure 8: LO2 damper concept shown in the bottom of the LO2 tank

\section{F. Prepressurization}

The MPS portion of the Upper Stage is now in the "launch ready state" and is required to provide the capability to maintain this state for eight hours. When the launch window is approximately ten minutes away, final checks of the Upper Stage are performed. MPS provides helium from one of the ambient COPVs on the thrust cone (see Figure 6) for the final spin check of the Thrust Vector Control (TVC) system. The helium is used to spin up the turbine and provide hydraulic power immediately prior to prepressurization and launch. The ambient helium depleted to spin up TVC is replenished by the ground system prior to launch. After all possible ARES I final system checks, the MPS enters prepressurization (approximately three minutes prior to launch - see Figure 5).

Prepressurization of the propellant tanks occurs when the ground system provides high pressure helium through sealing QDs to each of the propellant tanks, which is followed by propellant tank vent/relief valve closure by the MPS. The hydrogen tank prepressurization helium enters through a sealing QD on the Instrumentation Unit umbilical plate and passes through a check valve and the LH2 tank diffuser before it is sent into the LH2 ullage. Figure 1 shows the LH2 diffuser in the top of the LH2 tank. The helium is chilled to cryogenic temperature by a ground heat exchanger located on the MLP. Similarly for oxygen tank prepressurization, the helium enters through a sealing QD on the aft skirt and is routed through the LO2 tank snorkel, which is inside the LO2 tank, to the LO2 tank diffuser and ullage. Figure 7 shows the LO2 tank diffuser in the top of the LO2 tank. The additional complexity in the LO2 tank is due to a requirement that prevents penetration of the common bulkhead between the LO2 and LH2 tanks. It is important to keep the time between prepressurization and launch short as once the propellant tanks are prepressurized the propellants will no longer boil-off. The propellant won't boil as it is subcooled and the heat entering the tank through the walls will create a layer of warmer, stratified propellant that the 
USE cannot use, increasing the un-usable propellant that must be carried to orbit (which is a direct payload loss). MPS is sized for a two and a half minute prepressurization duration with a nominal one minute hold and two minute contingency hold for a total of five and a half minutes without boil-off prior to lift-off. Additional time in the prepressurized state may result in the inability to provide sufficient usable propellant to the USE in order to complete the mission.

\section{G. Flight Operations}

After vehicle lift-off, the liquid propellant, which is colder than the ullage gas even with cryogenic prepressurization, can further cool the ullage gas, causing the pressure in the ullage to decrease below the level required to start the engine. This cooling process is increased by waves in the ullage and propellant sloshing due to vehicle loads. In order to maintain the pressure above required levels, ambient high pressure helium stored in a COPV on the thrust cone, see Figure 6, is routed through a repressurization control panel into the LH2 or LO2 tank ullage. Repressurization is controlled through on/off solenoids, as the large ullage relative to the repressurization flow rates allows this simple bang-bang control setup to provide sufficiently smooth control. Repressurization starts at vehicle lift-off and continues through Upper Stage separation and USE start. The exact sequence for the changeover from repressurization to pressurization will be determined during the Integrated Stage Test which is a ground test of the full up flight US without RCS and ullage settling motors installed.

LO2 pressurization begins after USE start (or at most a few seconds prior to USE start). The cryogenic helium stored in the ten cryogenic helium spheres in the LH2 tank is routed down to the thrust cone and through the cryogenic helium regulator panel (see Figures 1 \& 6). After exiting the cryogenic regulator panel the flow is split - a portion is routed to the USE and heated in a heat exchanger downstream of the gas generator and a portion is sent through a heat exchange bypass and mixed with the heated helium. The bypass helium is mixed with the USE heated helium to control the temperature (using fixed orifices) to a lower temperature that will not damage the common bulkhead between the LO2 and LH2 tanks. A higher helium temperature enables lower helium usage, however higher temperatures increase the thermal difference across the common bulkhead and the resulting thermal strains. Limiting the helium pressurization temperature decreases performance but is required to maintain adequate structural margins on the common bulkhead. The mixed helium is flowed through a pressurization control panel, which modulates between high and low flow to control the LO2 tank ullage pressure within the desired control band, up the LO2 tank snorkel and out the diffuser into the LO2 tank ullage. Prior to the pressurization control panel, some of the mixed helium is routed to the POGO accumulator (see Figure 9) to charge it with helium gas.

LH2 pressurization can only occur after the USE starts as the gaseous hydrogen supplied from the engine to the MPS system is tapped off of the LH2 cooling jacket around the USE main combustion chamber and only flows once the USE main fuel valve is opened. The tapped off gaseous hydrogen is routed from the USE to the MPS gaseous hydrogen pressurization control panel, located on the thrust cone (see Figure 6), up the side of the LH2 tank to the LH2 diffuser, and into the LH2 tank ullage. Similarly to the LO2 tank, the LH2 pressurization panel modulates between high and low flow to maintain the tank ullage pressure within the control band. The gaseous hydrogen is also routed to the TVC turbine system to provide hydraulic power to gimbal the USE.

POGO suppression was added as a design requirement for the MPS at our Preliminary Design Review in April 2008. This system design is described in detail in the paper, "Design Analysis of the Ares I POGO Accumulator," by Swanson, L.A., and Giel, T.V. ${ }^{2}$. A cross-section of the POGO system is shown in Figure 9. The POGO accumulator is a volume wrapped around the outside of a portion of the LO2 feedline that is partially filled with helium and the remainder is $\mathrm{LO} 2$. The POGO accumulator helium volume removes pressure oscillations of a certain frequency - decoupling the liquid feed system from the USE induced pressure oscillations. The POGO accumulator is charged with helium gas at USE start from the LO2 pressurization helium supply and the liquid level is maintained with a constant helium flow and an overflow pipe throughout USE operation. 


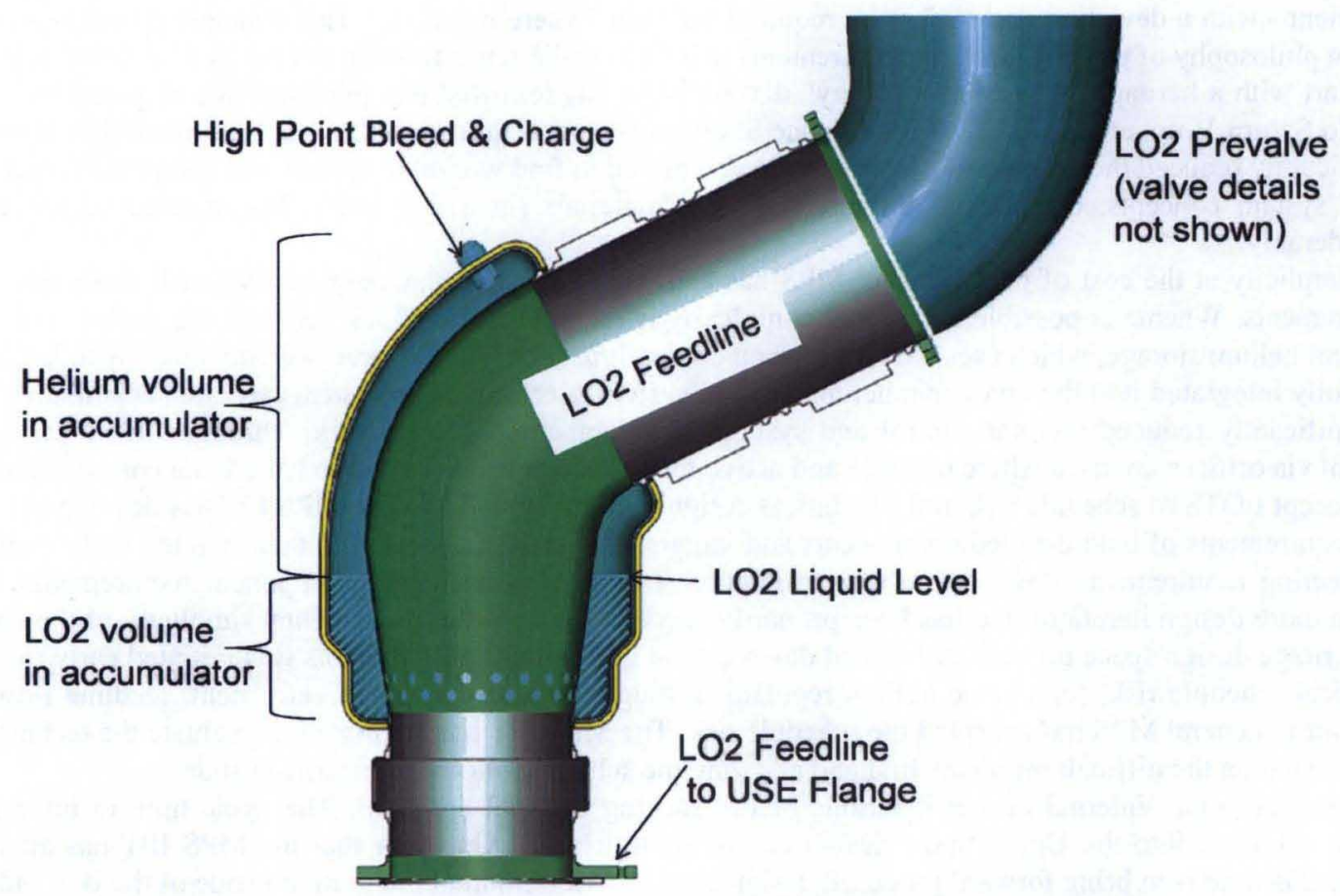

Figure 9: Section through the LO2 feedline showing the POGO accumulator

Thrust Vector Control of the USE is powered by either regulated ambient helium (prior to USE start) or gaseous hydrogen from the USE (tapped off immediately prior to the LH2 pressurization control panel). These sources of high pressure gas are supplied to the TVC system, which routes them through a turbine that powers a hydraulic pump to actuate the USE. Switching between gaseous hydrogen and helium is performed by the TVC system using pneumatic controls. TVC helium gas flow is started slightly prior to USE start and transitions to gaseous hydrogen a few seconds after USE start until USE shutdown.

Main Engine Cut Off (MECO) occurs after the stage has reached a predetermined measured velocity (rather than using a set time). The USE shuts down without requiring any MPS valves to change state (unlike the Space Shuttle, which uses the LO2 prevalve as a turbine brake). At MECO the LO2/LH2 tank ullages are inside of the pressurization control band and will gradually drift down in pressure as the remaining liquid mixes and cools the pressurant gas in the tank ullage. Eventually the incident solar radiation will heat the fluid mixture in the propellant tanks and increase the pressures to the point where the relief valves will vent the tanks, although this occurs after reentry begins. Within 120 seconds of MECO, Upper Stage electrical power is potentially unavailable and all MPS valves will move to their normal positions. A short period of time later (on the order of 15 minutes) the Upper Stage reenters the earth's atmosphere and is destroyed.

\section{MPS Design Philosophy}

The MPS IPT is composed of many individuals from a variety of technical branches at the NASA Marshall Space Flight Center, each of whom brings with them their individual and technical group's focus and philosophy of design. Some understanding of why the MPS IPT arrived at the current system design is useful in understanding the design itself.

Focus on the true requirement and push back on "desire-ments": The Constellation Project Office and lower level design teams were created at the same time, so to a good degree the design and requirements have evolved in parallel. The development of the Fault Tolerance (FT) requirements used in the design is a good example of these parallel paths. Initially the requirement was to design to two FT for all faults that could cause loss of mission and/or loss of crew (and neglect the fault tolerance benefit of the abort system). As was discussed previously ${ }^{1}$, the MPS IPT chose to deviate from this early requirement and work to 1 FT where practical for mission success and 2 FT where practical for loss of crew. This has been accepted by the Constellation Safety Engineering Review Panel as 
sufficient - with a deviation approval to be required for each "where practical". This example points to a core MPS design philosophy of pushing back on requirements that don't make sense from an overall system point of view.

Start with a heritage "no new technology" design: MPS has followed this guideline where possible - using the Apollo Saturn V upper stage (S-IVB) and Space Shuttle systems as guideposts to follow. This design reference has significantly reduced the number of design iterations required to find workable system and component solutions. Reusing system concepts, component designs, and even materials (in a few cases) has accelerated the workflow considerably.

Simplicity at the cost of performance: MPS has actively focused on the simplest approach that meets the hard requirements. Whenever possible, additional complexity is required to "buy" it's way into the design. For example, ambient helium storage, which uses COPVs located on the thrust cone, could have been achieved with less mass if it was fully integrated into the cryogenic helium storage system. Keeping these systems separate cost mass - however it significantly reduced thermal control and systems development cost and work. Throughout the MPS, passive control via orifices are used where possible and active feedback control is limited to bang-bang control bands.

Accept LOTS of schedule risk in the technical design/requirements flow: The MPS IPT has developed the design and requirements of both detailed components and integrated systems in parallel, rather than the traditional systems engineering requirements flow, where system requirements flow down to the component requirements. This has driven more design iterations and has been primarily successful due to the fundamental simplicity of the design and the heritage design space utilized. Advanced development of several high risk items was initiated early to lower the technical schedule risk, (cryogenic helium regulator testing, prevalve concept development, feedline flow testing, etc.) but in general MPS has accepted the schedule risk. The MPS IPT has attempted to evaluate the technical issues by focusing on the difficult problems first and allowing the schedule of other concerns to slide.

Complete rapid internal design iterations before seeking external approval: The cycle time to integrate MPS design solutions into the Upper Stage design can be quite lengthy. One way that the MPS IPT has attempted to reduce this time is to bring forward proposed design changes with minimal integration inside of the IPT and propose them for approval. This may seem counter-intuitive but asking team members to "sign-up" to a change has driven some extremely fast design iterations inside of the IPT. Once the MPS IPT has run through the design iterations to obtain IPT approval, the systems group then works through the board approval process that integrates these design solutions with the various IPTs across the Upper Stage and ARES I stack. This integration across the Upper Stage and vehicle is quite lengthy but the MPS IPT will "lean forward" in almost all cases and work as if the design change approved by the IPT is the vehicle approved design.

\section{Lessons Learned}

The design process is always a learning process and the MPS design process has been no exception in that regard. The MPS IPT has and will continue to implement lessons learned from previous projects. However, the MPS IPT has had the pleasure of re-learning some of these lessons and perhaps developing a few more. Several of the most prominent ones are discussed in this section in order to pass this helpful knowledge.

Early in the design process, the Ares I MPS team attempted to achieve some commonality with the ARES V Earth Departure Stage (EDS) in order to lower the future costs of that stage. This "desire-ment" was overvalued early on in the design process and drove some design decisions that were later revised. For example, the electrical LO2 recirculation pump was not considered for removal from the design significantly later than was necessary, because of the EDS conceptual design requirement levied on it.

Assuming heritage hardware means that heritage requirements are assumed as well. As mentioned above, the design space was assumed to have no new technology development and was to use the Apollo Saturn IVB stage and Space Shuttle design solutions whenever possible. However, once a heritage design or component is selected, the requirements that were used to design that heritage component have also been selected. Adding more severe environments and/or requirements (for additional levels of seal redundancy for example) significantly changes the heritage designs - removing much of the benefit of the heritage design/component that was desired.

The design areas that were considered relatively straightforward have not always been easy to implement. In order to meet our design schedule, the MPS IPT decided to leave "easy" sections of the design out in order to focus on more difficult problems. For example, the MPS purge systems were left out of the integrated design until a few months prior to the Preliminary Design Review. The purge systems are relatively simple, including only lines and some check valves, but required significant integration with ground systems design. Because the purge solution selected by the MPS IPT required ground system modifications and the ground systems design team deals with the integrated vehicle stack level requirements, the problem became much more difficult than initially recognized. 
The relative significance of competing design goals like simplicity, fault tolerance, mass, schedule, and cost evolve with the design. Historically, in all of the NASA launch vehicle development programs, "mass is king" toward the end of the design process. In other words you will optimize the design to reduce mass over simplicity, cost, and schedule. Early in the design process MPS selected several design solutions with this in mind. For example MPS selected the cryogenic helium system for LO2 pressurization in order to lower overall MPS system mass (and increase safety) at a significant cost, schedule, and complexity impact. Our current design space considers "cost as king" and the design is accepting mass increases that would not have previously been considered in order to save cost and schedule.

It is important to avoid the selection of overly conservative initial design concepts. NASA's focus on safety has driven the design, leading to a tendency to make initial design concepts very conservative. The MPS IPT systems team initially proposed a fairly complicated prevalve pneumatic control scheme that satisfied all of the fault tolerance requirements ${ }^{1}$ but required eight times more mass than a simpler solution. Changing from this "conservative" design to a simpler design was quite difficult, although it was eventually determined to provide an acceptable level of fault tolerance with one eighth of the mass. The lesson learned from this is to propose the best overall design solution, so that it is displayed for the team to work to, even if it does not meet all design goals. Alternate design solutions should be discussed off-line. This is a difficult lesson to learn as we still attempt to meet all the requirements without pushing back.

\section{Summary}

MPS does not physically exist as a system separate from the Upper Stage. The "big bag-of-parts" from the MPS component vendors becomes the MPS only when it is assembled with all of the other systems on the Upper Stage. MPS interacts with every other system on the Upper Stage and an understanding of how MPS operates enables all of the engineers working on the Upper Stage to work from a common understanding of functions and terminology. This overview is offered to provide a top level view of MPS operations, a little of why the MPS IPT selected particular design solutions, and a few lessons learned in an attempt to assist this common understanding.

\section{References}

${ }^{1}$ Quinn, J.E., Chojnacki, K.T., Russell, F.J., Sexton, S.R., and Summers, C.A., "Fault Tolerance Philosophy for the NASA Crew Launch Vehicle (AREA I) Upper Stage Main Propulsion System," JANNAF 54 ${ }^{\text {th }}$ JPM, May 14, 2007.

${ }^{2}$ Swanson, L.A., and Giel, T.V., "Design Analysis of the ARES I POGO Accumulator," AIAA Joint Propulsion Conference, Aug. 2, 2009. 